\title{
8
}

\section{AS RELAÇõES ENTRE CONHECIMENTO, MÉTODO E DIDÁTICA NA PEDAGOGIA HISTÓRICO-CRÍTICA*}

Tiago Nicola Lavoura

Ana Carolina Galvão

A possibilidade de conhecer o real envolve a necessidade de considerarmos um abrangente e decisivo conjunto de elementos relacionados à problemática da constituição do ser social. Longe de querermos elencar uma lista com indicação de sucessivos aspectos que linearmente apontam para problemas/soluções desta questão relacionada à formação humana, daremos destaque ao lugar que a escola e o trabalho educativo ocupam - ou podem vir a ocupar - como forma de contribuir para este fim.

Todavia, não é qualquer método e/ou didática que se realiza no interior da educação escolar que pode conduzir o processo de desenvolvimento dos indivíduos com vistas a atingir a finalidade de formar sujeitos com a capacidade de 'inteligibilidade do real'. Assim, procuraremos neste capítulo desenvolver uma reflexão sobre aquilo que entendemos ser essencial das relações que se estabelecem entre conhecimento, método pedagógico e a didática histórico-crítica.

É importante apontarmos que estas relações que se travam no âmbito da teoria pedagógica histórico-crítica não estão reduzidas à questão epistemológica. As mediações que se fazem presentes entre as possibilidades de conhecimento do real e o método e a didática como interposições necessárias para a realização do trabalho educativo históricocrítico não sucumbem ao epistemologismo que assola a educação escolar.

Esse fenômeno - o epistemologismo pedagógico da educação escolar - não é algo novo. Na verdade, suas raízes remontam à própria gênese do processo de constituição das duas principais correntes pedagógicas que se edificaram no interior do desenvolvimento dos sistemas

*DOI - 10.29388/978-65-86678-91-8-0-f.179-200 
de ensino moderno: a pedagogia da essência tradicional em sua vertente laica e a pedagogia da existência escolanovista (SUCHODOLSKI, 2002).

Ocorre que esse fenômeno tem se intensificado sobremaneira e dramaticamente nos últimos quarenta anos, mais precisamente, sendo uma das consequências das transformações societárias ocorridas desde os anos de 1970 no quadro da crise estrutural do capitalismo contemporâneo (NETTO, 2017a). A rigor, a dinâmica cultural do tardo-capitalismo incorpora as características próprias do acentuado processo de esgotamento de todo e qualquer padrão civilizatório condizente com novas e necessárias formas de humanização dos indivíduos em meio ao processo de reprodução social.

Assim, a cultura que hoje se afirma e se cria na sociedade burguesa é uma cultura aprisionada à imediaticidade reificante e reificada da cotidianidade alienada, circunscrita à fungibilidade da cultura de consumo, cuja dinâmica se submete à própria lógica da obsolescência programada da produção de mercadorias na ordem do capital.

A escola, ao longo destes anos, não ficou alheia a essa dinâmica cultural da sociedade tardo-burguesa. Ao contrário, ela como um todo e, em sua dinâmica, as práticas pedagógicas e respectivos postulados teóricos parecem não escapar do movimento de "[...] translação da lógica do capital para todos os processos do espaço cultural" (NETTO, 2017a, p. 68, destaque do autor).

Não à toa se evidencia o florescimento de supostas novas teorias pedagógicas que, a despeito de seu mantra autointitulado de 'pedagogias inovadoras', metamorfoseiam seus fundamentos com rótulos sedutores e mistificadores com vistas a não revelar a própria estrutura de suas bases teórico-metodológicas ${ }^{1}$ colocadas em consonância e a serviço da reprodução ampliada do capital em meio à sua crise estrutural.

\footnotetext{
${ }^{1}$ É sempre oportuno sugerir a leitura de Saviani (2011a), conferindo a análise precisa e desmistificadora que o autor faz das 'novas' ideias pedagógicas que passam a circular no cenário educacional brasileiro a partir dos anos 80 do século XX, rigorosamente vinculadas ao clima cultural pós-moderno e à ideologia neoliberal. A despeito de suas expressões intercambiáveis e da volatilidade de suas formulações teóricas (neoprodutivismo, neoescolanovismo, neoconstrutivismo e neotecnicismo), todas elas não escapam à entificação da semiologização do real, esfumaçando a realidade em representações subjetivas a partir de métodos pedagógicos cujos procedimentos de ensino hipertrofiam as chamadas experiências significativas, os saberes da prática, competências e habilidades, o cotidiano e o aprender a aprender. De igual modo, apregoam o discurso da adaptabilidade, do empreendedorismo, da desregulamentação do trabalho educativo, da 'abertura da escola', das reformas políticas e da privatização.
} 
Nessa toada, surge uma maré montante de métodos de ensino que, salvaguardando aparentes diferenças e algumas especificidades de suas próprias dinâmicas estruturais e sistemas de mediações - o que não dispensa a exigência de investigações determinadas e concretas para a identificação e compreensão de suas complexas articulações -, estão substantivamente vinculados a este fenômeno do epistemologismo pedagógico, solapando o ideário educacional com formas de aprendizagem especulativas que, por sua vez, exigiria um receituário de formas de ensino vistas como criativas, dinâmicas, ativas, individualizadas, adaptativas e plurais. Nos dizeres de Netto (2017b, p. 191, destaques nossos):

Os fenômenos conexos à reificação das relações sociais, ao aprofundamento da divisão sociotécnica do trabalho, ao parasitismo social e à ambiência generalizada do que Lukács, na esteira de Marx, sinalizou como "decadência ideológica" constrangem vigorosamente os esforços para pensar ontologicamente a vida social. Nesse marco, compreende-se que as orientações e direções intelectuais predominantes sejam aquelas marcadas alternadamente pelo epistemologismo, pelo formalismo e pelo empirismo, condutos diversos pelos quais a razão analítico-formal é entronizada como o espaço da racionalidade.

Consideramos que a atual conjuntura político-educacional e cultural-ideológica ${ }^{2}$ exige da pedagogia histórico-crítica uma radical e sistemática análise acerca deste problema central, que envolve as relações essenciais entre método/didática e as possibilidades de a prática educativa se realizar enquanto atividade dirigida à necessidade de formação de sujeitos com capacidade crítica de conhecer, sentir e agir na prática social, fazendo valer concretamente o postulado de Saviani (2011b) de educação como mediação e que metodologicamente possui a prática social como ponto de partida e de chegada da prática educativa.

Ao mesmo tempo, coloca-se como exigência para todos os educadores brasileiros concatenados com este projeto de formação

\footnotetext{
${ }^{2}$ Fazemos alusão ao avanço das forças conservadoras e reacionárias, ultraliberais e protofas cistas que, na atualidade, disseminam uma ambiência de ataque à razão crítica, à educação pública e ao trabalho educativo realizado com vistas a todo tipo de formação humana que rejeite a naturalização dos acontecimentos histórico-sociais como meros acontecimentos do cotidiano. Parece-nos claro, não obstante, que esta atual ambiência obscurantista, pragmatista e negacionista é caudatária da história, e que suas raízes podem e devem ser apreendidas com a devida radicalidade para seu enfrentamento.
} 
humana a apreensão radical da dimensão ontológica do trabalho educativo histórico-crítico ${ }^{3}$, o que requer retomar o problema da formação humana articulada à compreensão do modo de ser e reproduzir-se do ser social de forma historicamente concreta. Vejamos como é possível desenvolver esses elementos.

\section{O problema do conhecimento e da razão na história}

Como se sabe, a consolidação da ordem burguesa demandou um conhecimento desantropomorfizador da natureza e da sociedade. Novas necessidades advindas do avanço das forças produtivas e das relações sociais de produção da vida social no capitalismo exigiram e propiciaram a emergência da assim chamada 'razão moderna' (ANDERY et al., 1999), um vasto e complexo arco histórico do desenvolvimento da ciência e da filosofia que se inicia com o Renascimento e culmina na llustração, notadamente, vinculado ao período ascensionário da burguesia descrito por Lukács (2020).

Entretanto, também é conhecido entre nós que este período progressista, ascendente e orientado pela busca da elaboração de uma racionalidade edificada a partir das exigências concretas de luta da burguesia revolucionária contra o Ancien Régime - permitindo que pensadores como Giordano Bruno, Espinosa, Vico e Hegel, para não citar também a extensa referência do pensamento circunscrito às tradições empiristas e racionalistas do período, edificassem suas teorizações a partir do caráter racional dos processos histórico-sociais - será interrompido por uma nova etapa histórica caracterizada por Lukács (2020) como período da decadência ideológica burguesa.

O filósofo húngaro, seguindo as indicações feitas por Marx, analisa criticamente toda a inflexão do desenvolvimento do pensamento burguês a partir dos eventos revolucionários de 1848, produto das respostas efetivas dadas pela própria burguesia aos conflitos e confrontos contra o proletariado que, entre os anos de 1820 a 1840, passa a se organizar

\footnotetext{
${ }^{3}$ Mesmo que seja para mencionar, uma vez que não nos é possível desenvolver essa discussão neste texto, vale afirmar que a problemática da destituição das bases ontológicas do trabalho educativo se coloca na atualidade como uma questão vital, uma vez que ela se acelera de forma brutal e corrosiva na dinâmica do capitalismo virótico e pandêmico (ANTUNES, 2020), com os tentáculos do capital voltados para a implementação aparentemente irreversível do ensino digital, telepresencial, plataformizado e uberizado.
} 
efetivamente como classe em luta pelo avanço das transformações sociais que a outra - burguesia - abandonara ao se firmar como detentora do poder político e econômico na nova ordem social.

Como se vê, as determinações da decadência ideológica da burguesa refletem, por um lado, o esgotamento do seu próprio papel historicamente progressista e, de outro, seu trânsito ao campo de conservadorismo - sua busca, a partir destes episódios históricos, na luta pela conservação do existente. Conforme Netto (2010, p. 273), as expressões dessa decadência no âmbito das formulações teórico-filosóficas consistem "[...] na ruptura com a herança cultural do período anterior, na negação do caráter contraditório e transitório da sociedade burguesa e no evasionismo em face das questões decisivas da vida social".

Da análise conferida por Lukács (2020) a este período de decadência ideológica burguesa, tem-se destaque a categoria de irracionalismo, expressão daquilo que o autor denominou de 'a destruição da razão'. Em um texto volumoso e de robustez peculiar, ele busca examinar a elaboração cultural alemã tendo como objetivo compreender como foi possível o obscurantismo do nazifascismo ocorrer precisamente na Alemanha, uma vez que foi exatamente destas terras as mais brilhantes e ricas contribuições filosóficas do período de ascensão burguesa.

Revelar as elaborações filosóficas que prepararam ideologicamente o clima para a "[...] visão de mundo nacional-socialista" (Lukács, 2020, p. 10) torna-se objeto de análise e, nesta busca, o autor irá perquirir o caminho seguido pela Alemanha, no plano da filosofia, até chegar a Hitler. Assim, de Schelling à ideologia nazifascista de Chamberlain, entrecruzando os pensamentos de Weber, Nietzsche e Heidegger - que, de conjunto, possuem como alvo de ataque a filosofia de Hegel - deprecia-se simultaneamente as categorias de totalidade, historicismo, humanismo, razão e dialética, 'corrigindo' tais categorias e enaltecendo, no lugar destas, as categorias de intuição, subjetivismo, individualismo e pessimismo.

Disto resulta uma razão demolida, efetivamente, a destruição da capacidade racional de apreender a realidade em movimento. $O$ completo fechamento na subjetividade implica a inviabilização das mediações entre sujeito e mundo objetivo e, na ausência destas - das mediações - resta o encontro imediato do sujeito com a subjetividade e com a intuição, num mundo cujas vivências 'reais' e 'autênticas' seriam as vivências subjetivas (LUKÁCS, 2020). O autor concentra sua crítica, portanto, às filosofias subjetivistas privilegiando a contraposição entre razão e irracionalismo. 
Todavia, erige-se ainda outra vertente desta decadência ideológica da burguesia não analisada por Lukács efetivamente na obra $A$ Destruição da Razão. Trata-se da categoria da miséria da razão, posta em destaque com rigorosidade, originalidade e autenticidade - por Coutinho (2010). Conforme o autor, em torno de uma razão miserável - que se distingue, em partes, do irracionalismo - órbita um conjunto de formulações teóricofilosóficas que, formalmente racionalista, afirma positivamente apenas aquilo que se circunscreve aos dados e/ou fatos imediatos da realidade, aceitando somente a imediaticidade aparente do real cuja apreensão pode se fazer por intermédio do uso de uma razão analítico-formal de caráter instrumental.

Em suma, situam-se neste espectro as correntes positivistas e neopositivistas do pensamento moderno refratárias do período da decadência burguesa que, capitulando em face da totalidade da realidade, operam quase sempre à luz de certo epistemologismo sustentado por um agnosticismo - um ensurdecedor silenciamento sobre os aspectos essenciais da realidade, não revelados na faticidade empírica do real - e, portanto, aprisionadas à sua aparência reificada.

A contradição entre aparência e essência do real é da maior importância para a análise das relações que neste texto levantamos acerca das relações entre método/didática e a apreensão da realidade objetiva tal qual ela é em sua totalidade, em sua processualidade contraditória e em seu movimento histórico - no âmbito da realização do trabalho educativo, uma vez que a não superação da forma aparente da realidade tem consequências cognoscitivas para a reprodução ideal do concreto em pensamento. Coutinho (2010, p. 38, destaque nosso) coloca o problema com limpidez:

[...] quando o pensamento não tem condições de superar o imediatismo e o espontaneísmo, não pode superar a descrição da forma aparente e alcançar a reprodução da essência. Converte então essa forma aparente em fetiche, ao conceder-Ihe uma autonomia e universalidade que não possui.

Com efeito, o desmoronamento da contradição entre aparência e essência impede que a imediaticidade da aparência - a faticidade dos dados empíricos - dissolvam-se na totalidade que revela a essência, permitindo reconhecer tais dados fáticos como expressão singular de processos 
particulares. A imediaticidade, assim, impulsiona a razão a converter as contradições dialéticas imanentes do real em elementos cristalizados como dados isolados, impedidos de serem apreendidos na forma de um sistema de mediações constitutivos de uma totalidade rica e complexa.

Eis a caracterização da miséria da razão explicitada por Coutinho (2010), que - empobrecida - não transcende a mera descrição da imediaticidade aparente do real e faz com que, no máximo, a factualidade empírica seja classificada a partir do princípio da identidade e da antinomia lógico-formal.

De igual forma, importa destacar o caráter de complementaridade destas duas formas distintas de expressão da decadência ideológica da razão na ordem burguesa, qual seja, a impossibilidade de apreensão da essência da realidade humana: “[...] a filosofia da decadência torna-se, cada vez mais, um pensamento imediatista, centrado nas aparências fetichizadas da realidade" (COUTINHO, 2010, p. 36). Prossegue o autor:

Tanto a "destruição" quanto a "miséria" da razão, tanto o irracionalismo quanto o agnosticismo [neo]positivista ou estruturalista, ligamse a esse predomínio inconteste [...] capitulam diante do imediato, são incapazes de recompor no pensamento a essência dialética da objetividade. Em suma, aceitam como "condição humana" o dilaceramento histórico [...]. (COUTINHO, 2010, p.43-44, destaque do autor).

Como se vê, seja o cerco subjetivista da irratio no intuicismo da experiência imediata, ou o aprisionamento da miserabilidade da razão formal na imediaticidade fática, ambas operam com instrumentos ídeoteóricos próprios de uma razão plasmada na decadência da cultura burguesa, fazendo erigir formas de consciência e concepções de mundo conservadoras e/ou estabilizadoras da ordem comandada pelo capital. O trunfo desta decadência ideológica, promover a destituição da dimensão ontológica da razão moderna.

Decerto, não é qualquer forma de consciência ou de racionalidade que possibilita a constituição de individualidades humanas movidas pelas máximas possibilidades de realização do ser social na história. Referimo-nos à consciência filosófica edificada pela razão dialética, única forma lógicometodológica de reproduzir o real no pensamento tal qual ele - o real em sua dinâmica e devir - é em seu modo de ser efetivo, portanto, ontologicamente constituído na totalidade da prática social. 
A reconstrução ideal do movimento da realidade requer um árduo e laborioso trabalho - educativo ${ }^{4}$ - que envolve, diretamente, a necessidade da formação e desenvolvimento da consciência humana subjacente à razão dialética. Todavia, o referido trabalho está subordinado à acepção metodológica que fundamenta a atividade pedagógica e a didática histórico-crítica.

\section{Método pedagógico e a didática histórico-crítica a serviço do desenvolvimento da razão dialética}

Importa destacar que a isto que estamos caracterizando como razão dialética refere-se a uma dada racionalidade objetiva, que tende a refletir e/ou reproduzir a legalidade imanente do processo da realidade, a partir e por meio de um sistema lógico categorial capaz de reconstruir - no plano ideativo, da subjetividade e, por isso mesmo, da consciência humana - essa processualidade objetiva ${ }^{5}$.

Como se percebe, a razão dialética é, pois, suportada estruturalmente por seu caráter de objetividade e processualidade (NETTO, 2017b). Sua objetividade é determinada por sua própria estruturação, disposição e articulação que obedece a racionalidade do real, submetida ao princípio próprio do movimento da realidade contido no mundo objetivo. Ela - a razão dialética - tende a reproduzir as relações entre ser humano e natureza, dos seres humanos entre si e de suas manifestações contidas nas instituições sociais, nas classes sociais, nas objetivações humano-genéricas emanadas das atividades que o ser social realiza e que se acumulam historicamente na prática social.

É claro que ela é, ao mesmo tempo, uma racionalidade subjetiva, visto ser a reconstrução, na consciência, da racionalidade objetiva do real do princípio inerente ao real. Todavia, ela é fundada pela atividade do sujeito no mundo (LEONTIEV, 2004) e, assim, deve-se compreendê-la como unidade objetiva-subjetiva, constituída por polos distintos e contraditórios que agem de forma mútua, inter-relacionada e interdependente.

\footnotetext{
${ }^{4}$ Atentemo-nos para a relação necessária entre a educação escolar e o desenvolvimento do psiquismo humano, conforme já suficientemente discorrido pelos clássicos da psicologia soviética, bem como, explicitado nas produções subjacentes ao próprio campo de nossa teoria pedagógica e que tratam dos fundamentos psicológicos da pedagogia histórico-crítica e dos fundamentos pedagógicos da psicologia histórico-cultural. Sugerimos a leitura de Magalhães e Martins (2020), Martins (2013a, 2013b) e Martins, Abrantes e Facci (2016).

${ }^{5}$ Estamos nos valendo, portanto, da expressão razão dialética para designar a racionalidade do real edificada sob as bases do materialismo histórico-dialético.
} 
Mas o que importa destacar é que o caráter de objetividade da razão dialética supõe, portanto, a inadmissibilidade da destituição da dimensão ontológica da razão, tal como contrariamente ocorre conforme verificado na análise anterior a respeito da razão miserável lógico-formal e da razão destruída no irracionalismo, ambas subjacentes ao período da decadência ideológica burguesa. Não há e não pode haver fratura ontológica entre consciência e mundo objetivo na razão dialética. Marx e Engels (2007, p. 93-94) são absolutamente explícitos quanto a isto:

A produção das ideias [sic], de representações, da consciência, está, em princípio, imediatamente entrelaçada com a atividade material e com o intercâmbio material dos homens, com a linguagem da vida real. O representar, o pensar, o intercâmbio espiritual dos homens ainda aparecem, aqui, como emanação direta de seu comportamento material [...]. A consciência [Bewusstsein] não pode jamais ser outra coisa do que o ser consciente [bewusste Sein], e o ser dos homens é o seu processo de vida real. [...] Quer dizer, não se parte daquilo que os homens dizem, imaginam ou representam, tampouco dos homens pensados, imaginados e representados para, a partir daí, chegar aos homens de carne e osso; parte-se dos homens realmente ativos e, a partir de seu processo de vida real, expõe-se também o desenvolvimento dos reflexos ideológicos e dos ecos desse processo de vida. [...] Não é a consciência que determina a vida, mas a vida que determina a consciência.

Conforme explicita Netto (2017b), a fundação radical e consequente desta razão dialética exigiu, de fato, a elaboração de uma nova ontologia do ser social que, herdeira do pensamento ilustrado do período progressista de ascensão da burguesia e que encontrou em Hegel sua maior expressão, foi capaz de inverter a codificação hegeliana que condicionava o desenvolvimento histórico ao desenvolvimento do espírito (a ideia absoluta), desmistificando seu núcleo válido e racional - a dialética do idealismo objetivo filosófico.

Admitindo-se a premissa de que a didática histórico-crítica está a serviço do desenvolvimento desta razão dialética - desta forma lógicoracional capaz de apreender a realidade -, cumpre-se a tarefa de o trabalho educativo histórico-crítico identificar as formas mais desenvolvidas do saber objetivo produzido historicamente, convertendo-o em saber escolar, bem como, prover os meios necessários de sua assimilação (SAVIANI, 2011b). 
Esta tarefa não dispensa a necessidade de conhecer o modo por meio do qual se opera o desenvolvimento dos sujeitos-destinatários.

Assim, o tratamento dispensado pela didática histórico-crítica à tríade conteúdo-forma-destinatário (MARTINS, 2013a; GALVÃO; LAVOURA; MARTINS, 2019) coloca o conteúdo em relevo e centralidade para o trabalho educativo com vistas ao desenvolvimento da razão dialética. Com efeito, há uma relação de determinação entre conteúdos do ensino e conteúdos do pensamento. As formas mais desenvolvidas de consciência social humano-genérica (dentre elas a filosofia, as ciências e as artes) precisam se converter em consciência individual dos sujeitos singulares, permitindo-os conhecer a realidade, para nela intervir.

A escola precisa, então, selecionar os elementos culturais fundamentais para essa forma de humanização dos indivíduos e, para tal, o fundamento da didática histórico-crítica que afirma ser esta a realização de uma atividade cuja dimensão ontológica do trabalho educativo não pode ser desconsiderada é essencial (GALVÃO; LAVOURA; MARTINS, 2019).

Tal fundamento visa combater as tentativas de "[...] silenciamento da dimensão ontológica do ato de ensinar, reduzindo-o a um indigesto epistemologismo que apenas se pronuncia sobre o 'como ensinar'" (idem, p.139), convocando-nos a responder questões cuja centralidade ontológica se afirma em graus de determinação superior e fundamental para a organização do ensino e o desenvolvimento didático, tais como: 'o que é o trabalho educativo?', 'o que é o ser que se educa?' e 'qual o modo de ser possível de se desenvolver na prática educativa nesta ordem societária?'.

Trata-se de afirmar positiva e propositivamente que a escola não pode se furtar a garantir o que é essencial para que os seres humanos tomem para si, como segunda natureza, tudo aquilo que a humanidade já produziu histórica e coletivamente (SAVIANI, 2011b) e que, na atual ordem burguesa do tardo-capitalismo em crise estrutural, é substantivamente negado à classe que vive do trabalho, submetendo-a a uma racionalidade condicionada ao empobrecimento, aligeiramento e esvaziamento de conteúdos de ensino - que a impossibilite de reconhecer as forças sociais que a aprisionam e a colocam na condição de classe explorada.

É preciso, pois, valer-se do critério de clássico da pedagogia histórico-crítica. Expõe Saviani (2011b) que clássico é aquilo que resiste ao tempo, extrapolando o momento em que foi criado. As noções de permanência e referência o determinam, visto que tal critério "[...] capta questões nucleares que dizem respeito à própria identidade do homem 
como um ser que se desenvolve historicamente" (SAVIANI; DUARTE, 2012, p. 31, destaque nosso).

Há ou não aqui um fundamento ontológico expresso no critério de clássico, delimitando-o como um reflexo ideal da realidade objetiva que, subjetivado pelos sujeitos-destinatários na forma de uma segunda natureza, permite-lhes uma dada inteligibilidade do real? Tal fundamento permite ou não apreender relações entre conteúdos de ensino no âmbito da didática histórico-crítica e a formação humana com vistas ao provimento da razão dialética capaz de edificar uma forma de consciência ontologicamente determinada pelo conteúdo da história real e efetiva da humanidade em seu modo de ser e de reproduzir-se?

A luta protagonizada pela pedagogia histórico-crítica para que o trabalho educativo assegure o acesso ao patrimônio humano-genérico em toda sua complexidade e diversidade está fundamentada no pressuposto ontológico de que aquilo que se passa no interior das escolas é reflexo do desenvolvimento da própria história da humanidade.

Melhor dizendo: operando-se com o critério de clássico, o saber sistematizado convertido em saber escolar, resultante e resultado da própria atividade humana no âmbito das ciências, das artes e da filosofia da época atual ou precedente, é portador de objetivações humano-genéricas, condensando atividade humana latente, e pode ser apropriado pelos indivíduos singulares, desde que estes os reproduzam na forma de suas atividades (DUARTE, 2016).

É a conexão do saber sistematizado com os grandes problemas da humanidade - com as questões fundamentais e decisivas para o desenvolvimento da humanidade - que faz com que sua apropriação na educação escolar por indivíduos singulares seja uma forma de desenvolvimento da consciência singular que reproduz o desenvolvimento das substanciais formas de consciência social. Não por acaso Leontiev (2004) afirmou que por detrás dos momentos dramáticos da consciência individual, situam-se os momentos dramáticos de toda a humanidade.

O conteúdo dos clássicos revela a forma como os seres humanos se fazem na história, ou seja, o modo como se constituem enquanto seres sociais, o modo como produzem e reproduzem a sua própria existência. Tal saber, que se acumula na prática social na forma de um sistema de objetivações, porta em si elementos da objetividade do mundo humano, e sua apropriação na escola permite captar estes elementos da própria realidade social que, codificados na forma de conteúdos escolares, podem 
conformar-se como propriedades instituintes de uma razão dialética capaz de reproduzir conscientemente a formas de ser dos indivíduos em sociedade.

Não é mera coincidência que, no âmbito do método pedagógico, Saviani (2011b) tenha afirmado a categoria de prática social como ponto de partida e de chegada do trabalho educativo. A prática social é uma totalidade objetivamente estruturada, dinâmica e de caráter não indiferenciado, constituída por elementos com distintos níveis de interrelação. Produzida historicamente pelas diversas formas de atividade do ser humano - sendo o trabalho a forma ontológico-primária - em cada um dos modos de produção da vida situados concretamente, condensa um amplo e complexificado acervo de objetivações humano-genéricas altamente diferenciadas, dentre elas a ciência, a arte e a filosofia.

Sendo assim, a conversão deste saber sistematizado em saber escolar com vistas a prover a assimilação destes conteúdos por parte dos estudantes requer, do professor, compreender as relações entre educação e sociedade, entre escola e vida, entre conteúdos de ensino e os conteúdos da própria vida humana objetivados na prática social por meio das atividades realizadas pelo ser social ao longo da história. Saviani (2020, p. 273-274, destaque nosso) explicitamente afirma que os professores somente poderão cumprir o seu papel - mediante esta orientação metodológica - se “[...] previamente compreenderem a historicidade do mundo atual, capacitando-se a identificar os componentes educativos nele albergados". O autor é bastante assertivo quanto à relação entre método, didática e o conhecimento da realidade:

Eis porque o método da pedagogia histórico-crítica indica que o ponto de partida, a prática social, é comum ao professor e aos alunos, mas há uma diferença essencial do ponto de vista pedagógico: o professor tem, ou deveria ter, uma compreensão sintética da prática social, ao passo que a compreensão dos alunos é sincrética. Por isso cabe ao professor prover os meios para que os alunos, no ponto de chegada, ascendam ao nível do professor, atingindo uma compreensão também sintética da realidade social em que vivem (SAVIANI, 2020, p. 278, destaques nossos).

Ademais, essa afirmação também nos coloca o desafio de estabelecer os meios didáticos mais adequados para a transmissão dos conhecimentos artísticos, científicos e filosóficos mais desenvolvidos e 
humanizadores. Em vista disso é que outro fundamento da didática histórico-crítica aponta a exigência do domínio seguro do objeto do conhecimento e seus respectivos conteúdos a ser ensinado aos alunos por parte do professor (GALVÃO; LAVOURA; MARTINS, 2019).

Este fundamento didático histórico-crítico visa, por um lado, assegurar que o professor, a partir da referida compreensão sintética da prática social, seja capaz de identificar as formas mais desenvolvidas do saber sistematizado e o converter em saber escolar na forma de conteúdos de ensino. Por outro, possibilitar que a atividade de ensino se concretize como um 'bom ensino', que conforme caracterizou Vigotski, requer que cada aula seja um tempo e espaço de reprodução dos traços essenciais do objeto do conhecimento.

Quanto mais saturado o pensamento do aluno estiver com as determinações e o sistema de mediações que constituem os conteúdos representativos das formas de ser do objeto do conhecimento - visando a transformação qualitativa dos sujeitos-destinatários da aprendizagem e, portanto, da realização da categoria catarse em termos de método pedagógico -, mais este ensino corresponderá às exigências de o trabalho educativo estar imbricado à necessidade de edificação da razão dialética capaz de instrumentalizar os sujeitos para o enfrentamento radical dos problemas do mundo contemporâneo objetivados na prática social ${ }^{6}$.

Ao mesmo tempo, a busca pelas formas mais adequadas para o processo de ensino dos conteúdos clássicos é deveras importante, uma vez que as melhores formas impulsionam o desenvolvimento dos conteúdos. Se as formas não estão adequadas ao desenvolvimento dos conteúdos, elas passam a reprimi-los, a comprimi-los, tornando-se um entrave para o seu desenvolvimento. E conforme Galvão, Lavoura e Martins (2019, p. 104):

As formas pedagógicas adequadas são, portanto, todas aquelas que contribuam para a transmissão do saber escolar (fim a atingir). Em didática, isso se refere aos procedimentos, recursos e técnicas que permitem a efetivação dos conteúdos levando em conta os sujeitos a que se destinam (eis a tríade conteúdo-forma-destinatário).

\footnotetext{
${ }^{6}$ Verifique-se, neste pequeno trecho, como é possível articular e colocar em movimento as categorias do método pedagógico (prática social, problematização, instrumentalização e catarse), valendo-se deles - do método e suas categorias - para a fundamentação, organização e sistematização da didática histórico-crítica e, ao mesmo tempo, afastar-se de seus usos na forma de corriqueiros procedimentos de ensino.
} 
Então, é preciso lançar mão dos mais variados recursos e procedimentos, considerando a especificidade de cada área de conhecimento, de cada etapa da escolarização e de cada organização do ensino segundo seu projeto político-pedagógico. Por isso Saviani explica que "[...] não há métodos previamente condenados e nem métodos previamente consagrados, porque a escolha do método é sempre dependente da finalidade a ser atingida. É o fim a atingir que determina a escolha do método e dos procedimentos" (MARTINS; REZENDE, 2020, p. 20).

Além disso, as condições existentes são determinantes das formas. É ilusório o 'poder docente' de ensinar quando os recursos humanos e materiais disponíveis são escassos ou inexistentes. Isso não significa imobilizar a ação dos professores, mas planejar as atividades escolares conforme a realidade concreta (o que é inseparável da luta pela qualidade da educação, seu financiamento público, sua gestão democrática etc.).

Façamos agora algumas considerações sobre o terceiro elemento da tríade, o destinatário. Conteúdo e forma são elementos abstratos se não estiverem vinculados a um sujeito que aprende, ou seja, a quem se dirige ou se destina o trabalho educativo.

Segundo Marx (2010), o ser humano é um ser de pulsões e carências que se enriquece (humaniza) por meios diversos. Entre eles, está a escola e ser um entre outros não diminui a importância da educação escolar, tendo em vista se destinar a socializar o saber sistematizado (SAVIANI, 2011b).

De acordo com Martins (2013a), em termos psicológicos, os seres humanos precisam se apropriar da realidade objetiva subjetivando-a, pois é isso que permite torná-la inteligível. Como já afirmamos, a captação da realidade pela consciência depende do tipo de conteúdo que é dado ao indivíduo e que viabiliza o desenvolvimento das máximas possibilidades do psiquismo humano, sendo imperativa a atividade do sujeito. Por essa razão, a pedagogia histórico-crítica defende uma escola que se constitua como "uma rica totalidade de determinações e relações diversas" (MARX, 2008, p. 258).

A atividade à qual nos referimos não é mera ocupação e também não se trata daquilo que na escola chamamos comumente de 'atividades pedagógicas' para nos referir a determinadas tarefas (o exercício de língua portuguesa, a resolução de operações matemáticas, pintar um mapa etc.). Como explica Pasqualini (2016, p. 52): 
Atividade é um processo que se constitui de uma cadeia de ações, voltadas a determinados fins, os quais, encadeados, atendem ao motivo que impulsiona a atividade (sendo que o motivo reflete uma necessidade humana e identifica o objeto que a satisfaz). Atividade não é, portanto, sinônimo de ação ou de simplesmente "fazer alguma coisa".

A categoria atividade (que exige ações e operações) nos permite entender a relação do ser humano com o mundo, visto ser ela efetivamente a substância da consciência ${ }^{7}$ (LEONTIEV, 1980), nos subsidiando para compreender a própria dinâmica da periodização do desenvolvimento humano. Segundo Pasqualini e Eidt (2016, p. 103, destaque das autoras):

[...] ao analisarem as diversas atividades infantis [os autores da psicologia histórico-cultural] perceberam que elas não se encontram em um mesmo plano de hierarquia, ou seja, determinadas atividades têm papel mais decisivo do que outras a cada momento do desenvolvimento humano. A categoria fundamental para compreender o psiquismo infantil em desenvolvimento é, assim, o conceito de atividade principal, dominante ou atividade-guia. A atividade dominante é aquela responsável pela formação e reorganização dos processos psíquicos centrais de um dado período do desenvolvimento. Isso significa que em cada período do desenvolvimento uma atividade diferente guia o desenvolvimento psíquico. A atividade guia ou dominante não apenas forma e reorganiza processos psíquicos, mas gera novos tipos de atividade; dela dependem as principais mudanças psicológicas que caracterizam o período (LEONTIEV, 2001b). A partir da atividade dominante, surgem em cada período novas possibilidades de atividade para a criança. É justamente a mudança de atividade dominante ou atividade-guia que marca a transição a um novo período do desenvolvimento.

O conhecimento sobre a periodização do desenvolvimento dos sujeitos-destinatários é, portanto, crucial para o planejamento didático,

\footnotetext{
${ }^{7}$ Recordemo-nos que a categoria atividade é a chave heurística da psicologia soviética para explicitar as relações entre sujeito e mundo objetivo, visto que a formação da imagem subjetiva da realidade objetiva na forma de consciência requer a mediação de formas de atividades humanas que permitam compreender "[...] como, no processo de sua atividade, os indivíduos constroem sua imagem do mundo - mundo no qual vivem, atuam, o qual reconstroem e, em parte, criam" (LEONTIEV, 2004, p.52). Para melhor compreender as relações entre a teoria da atividade e a pedagogia histórico-crítica, conferir Pasqualini e Lavoura (2021).
} 
pois as formas deverão privilegiar ações e operações que a um só tempo atendam a atividade-guia de um dado período e impulsionem o indivíduo para outra atividade-guia, expressando seu enriquecimento psíquico. Do mesmo modo, os conteúdos serão organizados levando em conta os elementos característicos da atividade-guia e serão apresentados e reapresentados em diferentes etapas da escolarização, com graus de complexidade que aumentam em espiral crescente numa dinâmica dialética entre processos que combinam evolução e revolução na forma como os indivíduos se relacionam com a realidade.

Há, aqui, um pressuposto essencial, que nos remete à segunda característica do caráter estrutural da razão dialética, ainda por nós não diretamente explorado: referimo-nos à sua dimensão de processualidade. A formação de uma imagem subjetiva capaz de penetrar na processualidade do real, apanhando as determinações essenciais dos processos históricosociais que não se mostram na imediaticidade empírica - a não ser como forma aparente de 'fatos' naturais cotidianos -, requer uma racionalidade que se caracterize como movida substantivamente pela lógica dialética imanente da realidade.

Reproduzir intelectivamente o movimento da realidade exige uma forma lógica de raciocinar que rompa radicalmente com a faticidade imediata da cotidianidade, nada concedendo ao empírico, ao imediato, à factualidade fenomênica do real que, na ausência da possibilidade de sua superação, condiciona o pensamento à fetichização dos processos histórico-sociais, uma vez que a razão não se torna capaz de dissolver tal imediaticidade.

As determinações fundamentais da vida cotidiana - sua heterogeneidade, imediaticidade e superficialidade extensiva - nos marcos do capitalismo contemporâneo acaba por implicar uma forma de racionalidade em que o requisitado não é o conhecimento de processos e relações internas da dinâmica dos fenômenos sociais, mas sim, respostas funcionais às situações dadas. Instaura-se uma relação direta entre pensamento e ação, uma conduta imediatista e espontaneísta cujo critério de utilidade se confunde com o de verdade (NETTO, 2012).

A educação escolar, hegemonicamente tomada pelas pedagogias contemporâneas neopositivistas, neoprodutivistas e neopragmatistas, tem reforçado a formação desta racionalidade típica do período da decadência ideológica, conforme já atestamos. A racionalidade do mundo objetivo é aqui obstruída, seja pela sua completa negação - tendência da irratio -, seja 
pela via da lógica instrumental, culminando num comportamento meramente manipulador, quantificador e formalista - tendência da razão miserável. Não por acaso, temos a implementação da Base Nacional Comum Curricular (BNCC) $)^{8}$ no atual contexto educacional brasileiro, com sua lógica de formação humana por competências, em todos os níveis e segmentos educacionais, desde a educação infantil até a formação de professores na graduação e pós-graduação, expressão das 'reformas educacionais' impostas pelas agências do grande capital e de seus vassalos governos ultraliberais.

Advogamos ser a didática histórico-crítica um instrumento a serviço da edificação da razão dialética, visto um de seus fundamentos afirmar a concepção ampliada de eixo de ensino à luz da lógica dialética. Trata-se de conceber a organização do ensino a partir de uma sistematização lógica do saber escolar metodologicamente articulada e ordenada com base na ampliação espiralada do conhecimento, expressando o movimento dialético de sucessivas aproximações da relação sujeito-mundo objetivo. Desta feita, concebe-se a atividade de ensino como:

[...] uma processualidade formativa em que distintos graus de generalização da lógica de pensar se formam e se desenvolvem, configurando-se como verdadeiras referências que vão se ampliando de forma crescente e espiralada, revelando toda a riqueza da qualidade e da profundidade da penetração do pensamento na essência dos fenômenos da realidade social (GALVÃO; LAVOURA; MARTINS, 2019, p. 147).

Afirmar a necessidade de o trabalho educativo ser realizado com vistas ao ensino de conteúdos mais representativos das máximas possibilidades de apreensão da realidade - valendo-se do critério de clássico da teoria pedagógica histórico-crítica - requer, também, um planejamento didático-metodológico cuja forma lógica de organização e sistematização do conhecimento seja capaz de impulsionar o desenvolvimento da razão dialética, possibilitando uma racionalidade que supere os princípios da lógica formal.

A processualidade da razão dialética corresponde ao próprio movimento dinamizado pelas contradições e mediações da totalidade do real. A realidade, como um todo estruturado e orgânico, é uma totalidade

\footnotetext{
${ }^{8}$ Para uma análise histórico-crítica da BNCC, conferir Malanchen, Matos e Orso (2020).
} 
de máxima complexidade constituída por complexos de maior ou menor grau de complexidade. As relações entre tais elementos tensiona e transforma cada um destes complexos, bem como, a própria totalidade em si. Na sua imanência, há relações de interdependência e reciprocidade entre as partes e o todo - um sistema de mediações. As mediações são movidas e dinamizadas pela negatividade das forças contraditórias - a contradição - que impulsionam as formas de ser - aquilo que é - destes complexos em possibilidade do devir - aquilo que não é, mas pode vir-a-ser.

Totalidade, contradição e mediação são categorias ontológicas, pertencentes à própria estrutura do real. Somente a razão dialética é capaz de captar essa realidade tal qual é em si mesma, reconstruindo esse movimento no plano da consciência. Entretanto, este é um processo que não é imediato. A unidade lógico-histórica entre a objetividade do real e a racionalidade subjetiva reclama uma processualidade, por aproximações sucessivas.

A dissolução e ultrapassagem da faticidade empírico-fenomênica é, justamente, a análise das relações efetivas e essenciais, dos nexos internos, das determinações dinâmico-estruturais (estrutura e dinâmica) e históricogenéticas (gênese e desenvolvimento) que, recorrendo compulsoriamente à abstração, lança mão de um arsenal lógico categorial e conceitual ${ }^{9}$ fundado numa racionalidade que opera com sucessivos atos de generalização capazes de reproduzir o concreto em pensamento. Recorrendo a Kopnin (1978, p. 162):

O concreto no pensamento é o conhecimento mais profundo e substancial dos fenômenos da realidade, pois reflete com o seu conteúdo não as definibilidades exteriores do objeto em sua relação imediata, acessível à contemplação viva, mas diversos aspectos substanciais, conexões, relações em sua vinculação interna necessária. Abstrações isoladas levam o nosso conhecimento da apreensão do geral empírico ao universal, enquanto o concreto no pensamento fundamenta a conexão do singular com o universal, fornece não uma simples unida-

\footnotetext{
${ }^{9}$ Encontramos em Martins (2020) uma contundente análise dos processos gerais relacionados ao papel da educação escolar na construção do conhecimento, no desenvolvimento da consciência e na formação do pensamento teórico-conceitual. Quanto a estas relações, salienta a autora que a formação do pensamento teórico-conceitual capaz de refratar a realida de de forma consciente demanda, necessariamente, tomar o conceito à luz de seu traço essencial, qual seja, um sistema de significações objetivas enriquecido com as múltiplas determinações efetivamente existentes nos processos ou fenômenos da prática social.
} 
de de aspectos diversos, mas a identidade dos contrários (destaques no original).

Esta forma lógica de organização do ensino e sistematização de seus conteúdos propiciada pela didática histórico-crítica ancora-se, portanto, na própria resolução metodológica indicada por Marx concernente ao método do abstrato ao concreto, e que Saviani (2011b) delimitou em termos de método pedagógico como a passagem do empírico ao concreto, pela mediação das abstrações.

\section{Considerações finais}

Espelho da sociabilidade tardo-burguesa em sua crise estrutural, a decadência da razão moderna expressa uma ambiência cultural posta em marcha exatamente como ideologia: expressão de uma falsa consciência. Falsa, na medida em que, plasmada na faticidade empírica do real, não é capaz de reconhecer a historicidade dos processos sociais, tornando-os inteligíveis; mas, ao mesmo tempo consciência, na exata noção de que modula comportamentos e formas de ação dos sujeitos no mundo a partir de certo tipo de conhecimento - miserável, formalista, instrumental ou com tendência ao irracionalismo - permitindo o mover das individualidades na reprodutibilidade da vida cotidiana.

As pedagogias hegemônicas que se fazem presentes na educação escolar na contemporaneidade configuram este espírito do tempo do tardocapitalismo. Em termos formativos e pedagógicos, no limite, entificam uma razão empobrecida que, dentre inúmeros aspectos: aceitam a imediaticidade com que se apresentam os fenômenos histórico-sociais; não são capazes de distinguir aparência e essência da realidade; são incapazes de operar com as categorias de totalidade, contradição e mediação; interditam a dimensão ontológica da prática social, seja pela sua recusa, ou pela sua relativização; e, ora entronizam a semiologização do real, fazendo do conhecimento uma artefactualidade discursiva, ou, pervertem o real a uma dimensão instrumental à luz de uma atitude manipuladora do mundo, sendo o conhecimento subsumido à racionalidade analítico-formal.

Combatendo tais teorias pedagógicas e suas acepções didáticometodológicas anti-ontológicas, produtoras de um conhecimento fetichizador da realidade, a pedagogia histórico-crítica se firma e se afirma como aquela cujo fim a atingir é a humanização dos sujeitos com vistas ao 
conhecimento da realidade para nela intervir e transformar. Para tanto, não pode prescindir de um método e de uma didática orientados à edificação da razão dialética, cuja finalidade pedagógica é a de obtenção de uma autêntica racionalidade capaz de reproduzir a objetividade do mundo em seu movimento e contradições internas.

Nisto reside sua potência e vitalidade, não sucumbindo à atual e famigerada destituição da dimensão ontológica do trabalho educativo, ao tempo em que permite a restituição das relações entre escola e sociedade e entre indivíduo e gênero humano.

\section{Referências}

ANDERY, M. A. et al. Para compreender a ciência: uma perspectiva histórica. 8. ed. Rio de Janeiro: Espaço e Tempo; São Paulo: EDUC, 1999.

ANTUNES, R. Coronavírus: o trabalho sob fogo cruzado. São Paulo: Boitempo, 2020.

COUTINHO, C. N. O estruturalismo e a miséria da razão. 2. ed. São Paulo: Expressão Popular, 2010.

DUARTE, N. Os conteúdos escolares e a ressurreição dos mortos: contribuição à teoria histórico-crítica do currículo. Campinas: Autores Associados, 2016.

GALVÃO, A. C.; LAVOURA, T. N.; MARTINS, L. M. Fundamentos da didática histórico-crítica. Campinas: Autores Associados, 2019.

KOPNIN, P. V. A dialética como lógica e teoria do conhecimento. Rio de Janeiro: Civilização Brasileira, 1978.

LEONTIEV, A. A imagem do mundo. In: GOLDER, M. (Org.) Leontiev e a psicologia histórico-cultural: um homem em seu tempo. São Paulo: Xamã, 2004.

LEONTIEV, A. N. Actividade e consciência. In: V. MAGALHÃES-VILHENA (Org.) Práxis: a categoria materialista de prática social, volume I. Lisboa: Horizonte, 1980.

LUKÁCS, G. A destruição da razão. São Paulo: Instituto Lukács, 2020. 
MAGALHÃES, G. M.; MARTINS, L. M. Onze teses sobre a relação entre psicologia educacional e pedagogia escolar. Revista Educação em Questão, Natal, v. 58, n. 55, p. 1-21, e-19150, jan./mar. 2020.

MALANCHEN, J.; MATOS, N. S. D.; ORSO, P. J. (Orgs.). A pedagogia histórico-crítica, as políticas educacionais e a base nacional comum curricular. Campinas: Autores Associados, 2020.

MARTINS, L. M. O papel da educação escolar na formação de conceitos. In: GALVÃO, A. C. (Org.). 2. ed. Infância e pedagogia histórico-crítica.

Campinas: Autores Associados, 2020, p. 117-144.

MARTINS, L. M. O desenvolvimento do psiquismo e a educação escolar: contribuições à luz da psicologia histórico-cultural e da pedagogia históricocrítica. Campinas: Autores Associados, 2013a.

MARTINS, L. M. Os fundamentos psicológicos da pedagogia histórico-crítica e os fundamentos pedagógicos da psicologia histórico-cultural. Germinal: Marxismo e Educação em Debate, Salvador, v. 5, n. 2, p. 130-143, dez. 2013b.

MARTINS, L. M.; ABRANTES, A. A.; FACCI, M. G. D. (Orgs.). Periodização histórico-cultural do desenvolvimento do psiquismo: do nascimento à velhice. Campinas: Autores Associados, 2016.

MARTINS, M. F.; REZENDE, A. C. A consciência filosófica na pedagogia histórico-crítica: entrevista com Dermeval Saviani. Revista HISTEDBR Online, v. 20, p. 1-24, jul. 2020.

MARX, K. Manuscritos econômico-filosóficos. 4. reimpressão. São Paulo: Boitempo, 2010.

MARX, K. Contribuição à crítica da economia política. 2. ed. São Paulo: Expressão Popular, 2008.

MARX, K.; ENGELS, F. A ideologia alemã. São Paulo: Boitempo, 2007.

NETTO, J. P. Uma face contemporânea da barbárie. In: BRAZ, M. (Org.) José Paulo Netto: ensaios de um marxista sem repouso. São Paulo: Cortez, 2017a, p. 56-88.

NETTO, J. P. Razão, ontologia e práxis. In: BRAZ, M. (Org.) José Paulo Netto: ensaios de um marxista sem repouso. São Paulo: Cortez, 2017b, p. 175-195. 
NETTO, J. P. Para a crítica da vida cotidiana. In: NETTO, J. P.; CARVALHO, M. C. B. (Orgs.). Cotidiano, conhecimento e crítica. 10. ed. São Paulo: Cortez, 2012, p. 65-93.

NETTO, J. P. Posfácio. In: COUTINHO, C. N. O estruturalismo e a miséria da razão. 2. ed. São Paulo: Expressão Popular, 2010, p. 233-269.

PASQUALINI, J. C. Concepção de ser humano, educação e desenvolvimento. In: PASQUALINI, J. C.; TSUHAKO, Y. N. (Orgs.) Proposta pedagógica para a educação infantil do sistema municipal de ensino de Bauru/SP. Bauru: Secretaria Municipal de Educação, 2016, p. 41-68.

PASQUALINI, J. C.; EIDT, N. M. Periodização do desenvolvimento psíquico e ações educativas. In: PASQUALINI, J. P.; TSUHAKO, Y. N. (Orgs.) Proposta pedagógica para a educação infantil do sistema municipal de ensino de Bauru/SP. Bauru: Secretaria Municipal de Educação, 2016, p. 101-148.

PASQUALINI, J. C.; LAVOURA, T. N. Diálogos entre a pedagogia históricocrítica e a teoria da atividade: contribuições para o trabalho educativo. In: HERMIDA, J. F. (Org.). A pedagogia histórico-crítica e a defesa da educação pública. João Pessoa: Editora UFPB, 2021, p. 116-147.

SAVIANI, D. Infância e pedagogia histórico-crítica. In: GALVÃO, A. C. (Org.). Infância e pedagogia histórico-crítica. Campinas: Autores Associados, 2020, p. 247-280.

SAVIANI, D. História das ideias pedagógicas no Brasil. 3. ed. rev. Campinas: Autores Associados, 2011a.

SAVIANI, D. Pedagogia histórico-crítica: primeiras aproximações. 11. ed. Campinas: Autores Associados, 2011b.

SAVIANI, D.; DUARTE, N. A formação humana na perspectiva históricoontológica. In: SAVIANI, D.; DUARTE, N. (Orgs.). Pedagogia histórico-crítica e luta de classes na educação escolar. Campinas: Autores Associados, 2012, p. 13-36.

SUCHODOLSKI, B. A pedagogia e as grandes correntes filosóficas: a pedagogia da essência e a pedagogia da existência. São Paulo: Centauro, 2002. 